\title{
Profesores comunistas y sindicalismo docente en la lucha antidictatorial, Chile 1981-1987
}

\section{Communist teachers and teachers' unions in the anti-dictatorship struggle, Chile 1981-1987}

\author{
Christian Matamoros Fernández*
}

\begin{abstract}
Resumen
Durante la década de 1980 el Partido Comunista de Chile radicalizó su línea política en oposición a la dictadura militar, lo que trajo consigo la adopción de formas de lucha más combativas, audaces y violentas. Buscamos analizar las tácticas seguidas por los docentes comunistas en este periodo, los cuales contaban con una importante y antigua experiencia en el profesorado, pero que bajo estas nuevas condiciones adoptaron diversas tácticas entre la participación en una organización gremial dentro de las normas del régimen o en una organización sindical decididamente opositora.
\end{abstract}

Palabras clave: profesores comunistas, sindicalismo, radicalización, democratización, dictadura militar.

\begin{abstract}
During the decade of 1980 the Communist Party Chile radicalized its political line against the military dictatorship, which resulted in the adoption of struggle ways more fearless, combative and violent. We want to analyze the tactics used by the communist teachers in that period, who counted with former and important experience in the professorship, but under these new conditions adopted diverse tactics between participating in an organization within the rules of the regime and a union organization decidedly oppositional.
\end{abstract}

Keywords: Communist teachers, syndicalism, radicalization, democratization, military dictadorship.

Recibido: 10 septiembre 2016

Aceptado: 4 noviembre 2016

\footnotetext{
* Chileno. Licenciado en Filosofía PUCV; Magíster en Filosofía Política, Universidad de Chile; Candidato a Doctor en Estudios Americanos, mención Historia, Universidad de Santiago de Chile. Becario CONICYT 21130888.christian.matamoros@usach.cl
} 


\section{Introducción}

El Partido Comunista de Chile (PC) desde su fundación como Partido Obrero Socialista en 1912 contó con una considerable presencia de militantes en el magisterio. Su bolchevización en 1922 reforzó esta presencia, teniendo una importante participación en las luchas gremiales de esa década, en las discusiones pedagógicas y en los debates sindicales y políticos ${ }^{1}$.

De esta forma, en el magisterio comunista se fueron traduciendo debates similares a los que se daban en el escenario sindical y político nacional. Así por ejemplo, con la adopción en el comunismo internacional de la política de "clase contra clase" que implicaba desechar las alianzas con sectores calificados como reformistas, los profesores comunistas rompen en 1932 la unidad con los docentes socialistas y apolíticos presentes en la Asociación General de Profesores (AGP) y constituyen una organización sindical paralela: la Federación de Maestros de Chile. Esta fuerte politización de los profesores comunistas también se tradujo en la represión sufrida bajo los gobiernos de Ibáñez (1927-1931)², González Videla (19481952) ${ }^{3}$ y Pinochet (1973-1990), donde el PC fue ilegalizado.

Esta profunda imbricación del contexto político en que se desenvolvió el comunismo chileno y los docentes que militaban en dicho partido sufrió una importante tensión durante la década de 1980, debido al histórico proceso de radicalización política que experimentó el PC. Sin embargo, en los docentes esto no se tradujo en una interpretación inmediata o mecánica de dicha radicalización, como lo fue entre 1932 y 1935 donde los profesores comunistas en bloque abandonan la AGP en beneficio de la Federación de Maestros.

La implementación de una política partidaria que requería rígidos grados de clandestinidad - como la desarrollada por el PC durante este proceso de radicalización- trajo numerosas dificultades para aquellos militantes que ejercían una labor altamente pública y expuesta como es la docencia. Serán dichas dificultades y tensiones lo que en este artículo buscamos analizar, pesquisando los debates sobre las formas y tácticas sindicales adoptadas por los profesores de militancia comunista durante el periodo.

A partir de estas dificultades, la hipótesis de este artículo, plantea que los docentes comunistas buscaron de manera creativa implementar una táctica sindical acorde a la línea política partidaria, sin embargo esa táctica no fue unívoca, sino que varió entre los sectores que buscaban provocar cambios en las prácticas sindicales y quienes buscaban mantener aspectos de la tradición partidaria-sindical. Por una parte, un sector de profesores comunistas buscó implementar la radicalización política conformando una organización de

\footnotetext{
${ }^{1}$ Jaqueline Roddick, The radical teachers. The ideology and political behavior of a salaried "middle class" sector in Chile, 1920-1935, Ph. D. Thesis, University of Sussex.

2 Jorge Rojas Flores, La Dictadura de Ibáñez y los Sindicatos (1927-1931), Santiago, DIBAM-Editorial Universitaria, 1993.

${ }^{3}$ Valentina Orellana Guarello, "Profesores rojos" y "amenaza soviética". El alineamiento de la educación y la depuración de las escuelas durante la "guerra contra el comunismo" en Chile. 1947-1949. Tesis para optar al grado de Magíster en Historia, Santiago, Pontificia Universidad Católica de Chile, 2013.
}

.


educadores decididamente opositora a la dictadura, mientras que otro sector, más ligado a las tradiciones históricas de la militancia comunista buscó desarrollar esa política dentro de una organización institucional, donde se encontraban las amplias masas del magisterio y no solamente los profesores opositores.

Ambas tácticas representaron intentos por superar creativamente las dificultades de la radicalización política del PC para quienes ejercían un empleo altamente expuesto ante los aparatos represivos de la dictadura. A pesar de la carencia de una táctica sindical única, a partir de este análisis no hemos detectado casos de profesores comunistas que hayan rechazado abiertamente la mencionada línea política, situación que no fue la tónica en el resto de la militancia partidaria. Este último antecedente refuerza la idea de que dichas tácticas diversas fueron intentos por desarrollar la mencionada implementación a partir de continuidades y rupturas, entre el trabajo de masas público y la radicalización opositora, pero que no dejaron de provocar debates y tensiones internos.

Para fundamentar nuestra hipótesis nos basaremos en bibliografía secundaria, memorias testimoniales, entrevistas a profesores comunistas y revisión de prensa de la época.

La perspectiva de analizar las tensiones entre las militancias partidarias y las organizaciones sindicales busca saldar cuentas dentro de la historiografía respecto a la articulación existente entre las organizaciones sociales (en especial los sindicatos) y los partidos políticos, debido a que su tratamiento o bien ha confundido a ambos tipos de organizaciones o las ha separado unilateralmente. Gran parte de la escuela chilena de historia marxista clásica tuvo el importante acierto de incluir a los trabajadores dentro de la historia y de vincular a las organizaciones de trabajadores con la política, puesto que la historiografía conservadora limitaba la participación política para los "grandes personajes de la historia". Sin embargo, debido a una comprensión mecánica de la historia, el importante aporte de la historia social clásica no desarrolló un estudio de las organizaciones sindicales y los partidos entendiéndolos a partir de una relación, sino como una identificación absoluta, diferenciándose solamente como una etapa superior del desarrollo de la conciencia ${ }^{4}$. De esta forma, se estudió el tema como una sustitución, donde al estudiar al partido político de inmediato se estaba comprendiendo a las organizaciones sindicales, puesto que éstas constituían sus desarrollos primitivos.

Por otro lado, gran parte de la historiografía social desarrollada a partir de la década de 1980, buscó alejarse de estas posiciones sustitucionistas auto limitándose exclusivamente a lo "social", alejando cualquier tipo de participación política como una suerte de perversión o traición de lo social. Mediante esta fetichización de lo social se desarrolló una visión

\footnotetext{
${ }^{4}$ Hernán Ramírez Necochea, Historia del movimiento obrero. Antecedentes siglo XIX, Santiago, Editorial Austral, 1956.
} 
unilateral de la historia, donde las organizaciones sociales quedaban completamente separadas de los partidos políticos, sin establecer vasos comunicantes ${ }^{5}$.

La perspectiva historiográfica que aquí buscamos desarrollar comprende a las organizaciones sindicales y los partidos políticos dentro de una relación, la cual podrá ser mayor o menor, conflictiva o complementaria, pero casi siempre presente. En este sentido es que al enfocarnos sobre el PC lo hacemos a partir del mundo social-sindical donde actuaban los militantes, en la senda de una historia social de las organizaciones políticas.

Una perspectiva que ha buscado recientemente rescatar el componente político del movimiento sindical han sido los trabajos de Rodrigo Araya Gómez. Sin embargo, su limitación de "lo político" exclusivamente a las dirigencias sindicales y a las organizaciones de tipo superior (como las Centrales) viene a representar una historia del sindicalismo de los "grandes personajes" 6 , lo que vendría a reproducir algunas de los aspectos criticados a las corrientes clásicas, al realizar una historia social "desde arriba". No desechando para nada el importante rol jugado por las conducciones sindicales, nuestra perspectiva busca enfocarse en los discursos y prácticas sindicales del conjunto de los agentes sindicales, por lo que si bien son considerados las dirigencias sindicales, nuestro interés no se limita a ellas, sino que se extiende hacia las bases del magisterio.

\section{La presencia de la izquierda en el magisterio chileno}

El movimiento sindical chileno se caracterizó durante el siglo XX, entre otras cosas, por su fuerte vinculación con los partidos políticos ${ }^{7}$. De esta manera, se diferenció de otros movimientos sindicales latinoamericanos, donde los sindicatos mayoritariamente se vincularon de manera directa con el Estado más que con los partidos. Si a esto le sumamos que esa vinculación fue mucho más directa con los partidos políticos de izquierda que con los de centro o de derecha, podemos concluir junto a Zapata ${ }^{8}$ que el sindicalismo en Chile durante gran parte del siglo XX careció de un carácter corporativista al no subordinarse al Estado, precisamente por su autonomía respecto de éste y su fuerte vinculación con las organizaciones de izquierda.

En el profesorado, esta estrecha vinculación con los partidos tuvo algunas características diferenciadoras. Mientras que desde las primeras décadas del siglo XX el grueso del movimiento obrero estaba hegemonizado por los partidos de izquierda (comunista y socialista), en los docentes la mayor presencia la tuvo el Partido Radical (PR). Ahora bien,

\footnotetext{
${ }^{5}$ Gabriel Salazar, Labradores, peones y proletarios. Formación y crisis de la sociedad popular chilena del siglo XIX, Santiago, LOM Ediciones, 2000.

${ }^{6}$ Rodrigo Araya Gómez, Organizaciones sindicales en Chile. De la resistencia a la política de los consensos: 1983-1994, Santiago, Ediciones Universidad Finis Terrae, 2015; Rodrigo Araya Gómez, «Cambios y continuidades en el movimiento sindical chileno en los años 80. El caso del Comando Nacional de Trabajadores», Historia, ${ }^{\circ}$ 47, vol. 1, enero-junio 2014, pp. 11-37.

${ }^{7}$ Alan Angell, Partidos políticos y movimiento obrero en Chile, México, Ediciones ERA, 1974.

${ }^{8}$ Francisco Zapata, Autonomía y subordinación en el sindicalismo latinoamericano, México, Fondo de Cultura Económica, 1993.
} 
esto no quiere decir que en los docentes no hayan tenido presencia las organizaciones de izquierda, o que el sindicalismo docente haya estado alejado del resto del movimiento sindical $^{9}$.

La cercanía de las organizaciones docentes con el resto del movimiento sindical, estudiantil y político fue una constante, lo que provocó que varios líderes del magisterio se transformaran en importantes dirigentes de los partidos de izquierda, como Ricardo Fonseca, Luis Corvalán o César Godoy.

En la mayoría de estos casos los profesores comunistas tenían características comunes: provenían de familias de profesores, con un origen campesino o que recientemente habían dejado de serlo; en muchas ocasiones la militancia comunista provenía de su entorno familiar, mientras que en otros casos su vinculación a las organizaciones de izquierda se produjo mientras estudiaban en las Escuelas Normales (especialmente las cercanas a zonas campesinas).

La presencia de la izquierda chilena en el magisterio - especialmente socialistas y comunistas-, fue importante pero no hegemónica. A pesar de esto, "la disciplina y persistencia de sus cuadros parecía aumentar su real alcance" ${ }^{\text {"10 }}$, cuestión que también trajo resultados negativos para su papel de dirigentes sindicales, ya que debieron cumplir con variadas otras actividades o definitivamente "fueron extraídos de éste [el magisterio] para desempeñarse en otras esferas" ", como fue el caso de los mencionados importantes dirigentes del PC, o posteriormente con Gladys Marín ${ }^{12}$.

A mi parecer, esta migración de dirigentes docentes a cargos de dirección partidaria fue mucho mayor en el caso del PC que en el del Partido Socialista (PS) debido a que este último partido contaba con una mayor cantidad de cuadros formados profesionalmente desde donde podía echar mano (ingenieros, abogados y -especialmente- médicos). En cambio el PC, un partido de eminente extracción obrera, contaba con menos cantidad de cuadros formados educacionalmente, y los existentes provenían esencialmente del mundo artístico o intelectual, sin la capacidad de liderazgo de los docentes, los cuales estaban mucho más ligados al mundo sindical y campesino.

A pesar de esta presencia, en el grueso de los docentes primaron las posiciones más de tipo gremial que sindical y las corrientes ideológicas más ligadas a los sectores medios y burocráticos que al clasismo, lo que permitió que la hegemonía estuviera representada por

\footnotetext{
${ }^{9}$ La Federación de Maestros se afilió a la Federación Obrera de Chile y a la Internacional Sindical Roja; organizaciones docentes estuvieron presentes en 1936 en la constitución de la Confederación de Trabajadores de Chile y en 1953 en la Central Única de Trabajadores.

${ }^{10}$ Iván Núñez, Gremios del magisterio. Setenta años de historia, 1900-1970, Santiago, PIIE, 1986, p. 132.

${ }^{11}$ Idem.

${ }^{12}$ Profesora de enseñanza básica, diputada, secretaria general de las Juventudes Comunistas (1963-1974) y Secretaria General del PC (1994-2002). Fue presidenta de la Federación de Estudiantes Normalistas, pero sus responsabilidades políticas le impidieron desarrollar sus labores docentes.
} 
el PR y que a fines de los años 50 surgiera un importante sector ligado a la Democracia Cristiana (DC), especialmente entre los profesores con estudios universitarios.

\section{De la minoría activa a la izquierdización de fines de los años 60}

La hegemonía de los partidos de centro en el magisterio comenzó a ser disputada por las organizaciones de izquierda a fines de los años 60, dentro de una oleada que se desarrolló en toda Latinoamérica mediante procesos de izquierdización. Estos procesos se tradujeron en que las organizaciones adoptaran un mayor carácter sindical, único y que comenzaran a dejar atrás su aspecto gremial limitado exclusivamente a profesores, dando paso a organizaciones que reunieran a todos los trabajadores de la educación, puesto que se reconocían más como asalariados que como profesionales. Muestra de esto es la fundación en Chile del Sindicato Único de Trabajadores de la Educación (SUTE), en julio de 1970; el Sindicato Único de Trabajadores de la Educación del Perú (SUTEP), en julio de 1972; y la Confederación de Trabajadores de la Educación de la República Argentina (CTERA), en septiembre de 1973.

En este sentido, es que concordamos con Gindin cuando señala que "las corrientes de izquierda han crecido entre los trabajadores de la educación en los últimos 50 años" "13, lo que se traduce en que las organizaciones docentes busquen elementos comunes con el resto de los asalariados y articularse con otros sindicatos, además de tender hacia una "ruptura relativa con el ideario de respeto a las instituciones y al Estado que era constituyente de la identidad profesional en los orígenes de la expansión de la actividad"14.

Esto se vio reflejado en el caso chileno en: la larga huelga de 1968; la constitución del SUTE en 1970 y su importante rol jugado en el gobierno de Salvador Allende, donde brindó un decidido apoyo al proyecto de la Escuela Nacional Unificada, y respaldó al gobierno durante sus días más críticos, en especial cuando los gremios de camioneros y sectores de la aristocracia obrera (financiados por el sindicalismo "libre") intentaron el boicot general siguiendo la política de la derecha golpista.

Ahora bien, esto no quiere decir que el SUTE haya sido una organización conducida estrictamente por las organizaciones de izquierda o que haya agrupado exclusivamente a docentes de izquierda. Fue resultado del proceso de izquierdización política del periodo, donde las fuerzas centrífugas ganaron mayor presencia ${ }^{15}$, lo que se tradujo más que nada en su estructuración sindical: única (incluía en su seno hasta a los trabajadores del Ministerio de Educación) y con una connotación de asalariados y no de profesionales, profesores o educadores.

\footnotetext{
13 Julián Gindin, "Sindicalismo docente en América Latina: algunas consideraciones generales", en Julián Gindin (compilador), Sindicalismo docente en América Latina. Experiencias recientes en Bolivia, Perú, México, Chile y Argentina, Rosario, Ediciones AMSAFE Rosario, 2008, p. 28

${ }^{14}$ Idem.

${ }^{15}$ Es pertinente mencionar que entre 1958 y 1973 se publicó en Santiago "Educadores del Mundo", revista del magisterio comunista de circulación internacional, dirigida en su edición chilena por Crisólogo Gatica.
} 
La conducción del SUTE estuvo liderada por el PR, el cual era parte de la Unidad Popular $^{16}$, por lo que era apoyado por los profesores socialistas y comunistas, sin embargo en las elecciones internas de 1972, por lejos el triunfo lo obtuvo la DC alcanzando el $38,3 \%$, seguido por el PR con un $23,6 \%$, el PS con un $16,2 \%$ y el PC con un $8,4 \%$ (sumando la UP en total un 48,2\%). Sectores de la derecha como el Partido Nacional o el PIR (radicales de derecha) obtuvieron un $4,8 \%$ y un $5,2 \%$ respectivamente, mientras que el Movimiento de Izquierda Revolucionaria (MIR) obtuvo un $2 \%{ }^{17}$.

Este proceso de izquierdización de los docentes chilenos se vio violentamente interrumpido con la llegada de la dictadura militar en 1973, cuestión que recién se comenzaría a revertir de manera tímida a fines de los años 70, y a inicios de los 80 de manera un tanto más orgánica.

\section{Los profesores rojos tras el golpe}

Tras el violento golpe de Estado, gran parte del movimiento sindical quedó desarticulado, intervenido o dificultado de restablecer sus vinculaciones con las organizaciones políticas. El sindicalismo docente en particular sufrió la proscripción legal y la persecución de sus dirigentes más reconocidos. Tras la temprana represión, la dictadura llevó a cabo una imposición organizativa dentro de su proyecto corporativista -el cual sería luego abandonado-, teniendo como uno de sus escasos resultados positivos (que se arrastran hasta el día de hoy) la creación del Colegio de Profesores (CdP), en octubre de $1974^{18}$.

Desde esta fecha, y hasta 1981, los profesores chilenos estuvieron obligados a pertenecer al $\mathrm{CdP}$, el cual estuvo lejos de ser una organización que representase sus intereses, puesto que los cargos directivos eran nombrados por las autoridades de la dictadura, sirviendo más que nada como un organismo de control respecto a los posibles sectores disidentes del profesorado. Como si esto fuera poco, al CdP se les traspasaron todos los bienes e inmuebles confiscados a las anteriores organizaciones del profesorado.

Sumado a esta imposición organizativa, los profesores vinculados a las organizaciones de izquierda tuvieron aún otras condicionantes respecto a la reconstitución de su trabajo sindical. En primer lugar, los más reconocidos dirigentes del magisterio debieron partir al exilio o fueron exonerados, ante lo cual la inquietud de organizarse fue surgiendo lentamente por la iniciativa de profesores jóvenes, los cuales en su mayoría eran estudiantes

\footnotetext{
${ }^{16}$ Quienes condujeron el SUTE estuvieron ligados a los sectores del radicalismo que más se comprometieron con el gobierno de Allende, como Mario Astorga (vicepresidente del SUTE y luego Ministro de Educación del gobierno de Allende) y Humberto Elgueta Guerín.

17 Cristián Cox y Cecilia Jara, Datos básicos para la discusión de políticas en educación. 1970-1988, Santiago, CIDE-FLACSO, 1989, p. 25. El 8,4\% del PC representaba a 6.175 votos.

${ }^{18}$ Christián Matamoros, "Represión e imposición organizativa. Los primeros años del Colegio de Profesores de Chile (1974-1981)”, en Julián Gindin, Márcia Ondina Vieira Ferreira \& Sadi Dal Rosso (orgs), Anais do IV Seminário da Rede de Pesquisadores sobre Associativismo e Sindicalismo dos Trabalhadores em Educação, Niterói, Universidade Federal Fluminense, 18-20 de abril de 2013, Brasilia, Paralelo 15, 2013, pp. 105-120.
} 
en los años de la UP o recién se habían iniciado en la docencia ${ }^{19}$. Mientras que, por otro lado, las condiciones represivas impuestas por la dictadura, y la clandestinidad de organizaciones como el MIR o el PC, implicaron que "muchos de los profesores que por su militancia política formaron la resistencia a la dictadura debieron abandonar sus puestos de trabajo debido a lo altamente público de su desempeño, lo que dificulta cualquier tipo de medida de seguridad que se pudiera tomar al respecto, independiente de que siguieran sintiéndose como educadores" 20 .

En la vida interna del PC, a fines de 1976 y con severas condiciones de persecución y clandestinidad, se logró conformar una primera célula de profesores comunistas, la cual fue bautizada con el nombre de "Juan Gianelli". El crecimiento de esta célula obligó a formar otro grupo similar, que adoptó el nombre de "Fernando Ortiz"21. Luego de esto, a mediados de 1977, se estructuró el Equipo Comunista del Magisterio (ECM), liderado por Julio González y Ramón Meneses, desde donde se comenzó a discutir y conducir las acciones de los profesores comunistas.

Todas estas condiciones presentaron innegables cambios ante lo que clásicamente había sido el trabajo sindical docente de las organizaciones de izquierda. Ahora bien, esto no se tradujo directamente en un retroceso de las posiciones de izquierda, como ocurrió en el resto del movimiento sindical chileno, donde los sindicalistas democratacristianos ganaron mayor presencia. Esta persistencia de la izquierda y su posterior radicalización inclusive han sido reconocidas por sectores liberales, quienes señalan que "el continuo deterioro de las condiciones económicas y sociales del profesorado llevó inevitablemente al incremento de sus simpatías por las posiciones políticas antisistema"22.

El descontento provocado por las reformas neoliberales en educación - traducidas principalmente en la municipalización-, sumido en un contexto altamente represivo implicó que el carácter organizativo cambiara sus prácticas. Por esto, será al alero de los sectores progresistas de la iglesia católica y principalmente mediante manifestaciones culturales donde irá surgiendo una corriente de profesores disidentes y críticos de las políticas dictatoriales, los cuales al estar imposibilitados de constituir organizaciones sindicales o gremiales (hasta 1981, el CdP era la entidad única para los docentes)

\footnotetext{
${ }^{19}$ En 1985 , el $66 \%$ de los profesores chilenos tenía entre 0 y 15 años de ejercicio docente, es decir dos tercios habían comenzado sus labores docentes en los años de la UP o con posterioridad a 1973. Ver CPEIP, Censo Nacional de Docentes 1985, Santiago, 1986.

${ }^{20}$ Christián Matamoros, "Resistencias contrahegemónicas en el profesorado. Cultura política popular bajo la dictadura militar. 1976-1980", en David Aceituno y Baldomero Estrada (coords.), Miradas y reflexiones a nuestro pasado reciente. Actas de la I Jornada de Historia de Chile Contemporáneo, Edición Digital, Viña del Mar, Instituto de Historia PUCV, 2013, p. 178.

${ }^{21}$ «A la memoria de don Fernando Ortiz y de todos nuestros compañeros», El Siglo, Santiago, n 1027,16 de marzo de 2001, p. 21. Juan Gianelli fue un profesor comunista dirigente de la Unión de Profesores de Chile y del SUTE; fue asesinado por los organismos represivos de la dictadura en julio de 1976. Fernando Ortíz, fue profesor de historia en la Universidad de Chile, importante dirigente del PC, detenido desaparecido en diciembre de 1976.

${ }^{22}$ Carlos Neely I., Crítica a la reforma educacional, Santiago, Pehuén Editores, 2001, p. 40.
} 
constituyeron organizaciones de hecho, las cuales tuvieron su mayor hito organizativo con la formación en 1978 de la Coordinadora Metropolitana de Educadores (CME), que agrupaba a docentes disidentes (la mayoría militantes de organizaciones de izquierda) de la Región Metropolitana ${ }^{23}$.

Fue desde ese momento cuando en las organizaciones políticas de izquierda, en especial en el PC, comenzaron a surgir diversas posturas respecto a cuál debiese ser la línea de construcción sindical para los docentes. Así por ejemplo Jorge Pavez, profesor comunista que había dado sus primeros pasos en la docencia durante el gobierno de Allende y que no tenía mayores responsabilidades orgánicas, recuerda que a fines de los años 70 se comenzó a dar un debate entre los profesores comunistas determinado por aspectos generacionales: "la visión de los ex dirigentes del Sute se centraba más bien en la reconstrucción de lo mismo de antes, es decir que había que recomponer el Sute, y nosotros nos hicimos cargo de una nueva realidad y empezamos a trabajar con los profesores de aula en la base" 24 .

De esta manera, esos primeros encuentros de profesores opositores, entre los años 1977 y 1978 - que darían origen a la CME - , no fueron muy bien vistos por los dirigentes del PC en el magisterio; "yo en mi militancia como comunista iba informando de estas reuniones a los viejos y ellos decían, »no ahí está toda la gente del Mir los ultras, no este [sic] el camino compañero « y yo encontraba interesante el caminito",25.

Con el correr de los meses, el núcleo agrupado en torno a la CME afianzaría sus vínculos con las restantes organizaciones de las regiones de Valparaíso, Bío Bío y Maule, donde también aparecerían jóvenes militantes de partidos opositores, comunistas entre ellos. Mientras que las posiciones más tradicionalistas del magisterio, no tendrían ningún resultado práctico en la reconstitución del viejo SUTE, por lo que adoptarían una posición más pragmática a inicios de los años 80 .

Sin embargo, este debate de los profesores comunistas no se daba alejado de la lucha contra la dictadura, ni tampoco alejado del debate al interior del PC.

\section{La PRPM en los sindicatos}

Tras décadas de una línea política gradualista anclada en la lucha de masas y la contienda electoral, en 1980 el PC llama a "todas las formas de lucha" para derrocar a la dictadura; llamado evocado luego de un profundo debate interno que se materializó con la adopción de la Política de Rebelión Popular de Masas (PRPM). Este giro ha suscitado un amplio debate en cuanto a si corresponde a un "cambio de la línea política" o a un "giro al interior de la línea política" de este Partido ${ }^{26}$, lo cual no sólo se ha traducido a posteriori en un debate académico y político, sino que su anuncio, desarrollo e implementación suscitó un

\footnotetext{
${ }^{23}$ Organizaciones similares surgieron a inicios de los '80 en las regiones del Bío Bío y de Valparaíso.

${ }^{24}$ Entrevista a Jorge Pavez aparecida en José Ángel Cuevas, Materiales para una memoria del profesorado, Santiago, Editorial Colegio de Profesores, 2002, p. 86.

${ }^{25}$ Ibid., p. 87.

${ }^{26}$ Tomás Moulián e Isabel Torres, “¿Continuidad o cambio en la línea política del Partido Comunista de Chile?", en Augusto Varas (compilador), El Partido Comunista de Chile. Estudio Multidisciplinario, Santiago, CESOC-FLACSO, 1988, pp. 453-485.
} 
profundo debate al interior de los comunistas, que — según nuestro parecer- en el ámbito sindical fue dónde más resistencia tuvo.

El PC tiene su origen en el "heroico" movimiento obrero y se reconoce a ese carácter obrero como el núcleo más profundo de la cultura política comunista. Dentro de ésta es la lucha de masas la que ha concitado la mayor repercusión en la identidad comunista. Formas más radicalizadas como las del llamado "reinosismo" siempre fueron decididamente rechazadas, por representar ejemplos de aventurerismo y ultraizquierdismo que alejaban al partido de las masas ${ }^{27}$.

Los motivos por los cuales la PRPM no tuvo en el brazo sindical del PC los grados de radicalización que alcanzó en el ámbito estudiantil y principalmente poblacional, sin duda requieren de un estudio mayor y pormenorizado ${ }^{28}$. Lo que aquí planteamos, es que la misma tensión que se vivió al interior del PC "entre las tradiciones partidarias y las fuerzas que intentaban modificarlas" ${ }^{\text {} 9}$ también se manifestó en sus militancias sindicales, las cuales coordinadas bajo el CONASIN (Comisión Nacional Sindical), lograron desarrollar una autonomía relativa frente a la línea general del partido, lo que no negó que existieran ejemplos creativos y audaces de implementación de esta línea — como la desarrollada por dirigentes de la construcción (Sergio Troncoso y Héctor "el loco" Cuevas) o la minería (Moisés “el guatón” Labraña ${ }^{30}$ _- , pero siempre por dirigentes sindicales que habían tenido alguna experiencia previa ligada a aparatos de seguridad internos, autodefensa o en la génesis de la PRPM, no siendo la tónica general.

Ahora bien, esto no quiere decir que estos dirigentes hayan practicado una suerte de sindicalismo armado. La PRPM no fue una política exclusivamente armada o de "lucha armada", sino que incluía el componente armado. Por esto, lo que en realidad practicó un grupo de dirigentes sindicales comunistas fue intentar implementar en el sindicalismo la radicalización que estaba llevando a cabo el Partido, mediante prácticas audaces que sirvan para elevar la combatividad de las masas.

Llevar a cabo esta implementación no fue tarea fácil, la tensión detectada por Álvarez entre la ruptura que implicó la radicalización y la continuidad del trabajo de masas, se hizo mucho más fuerte en el ámbito sindical, debido a que la tradición del trabajo de masas en el

\footnotetext{
${ }^{27}$ Manuel Loyola, ““'Los destructores del Partido": notas sobre el reinosismo en el Partido Comunista de Chile", Izquierdas, Año 1, Número 2, diciembre 2008; V. I. Lenin, La enfermedad infantil del "izquierdismo" en el comunismo, Pekín, Ediciones en lenguas extranjeras, 1975.

${ }^{28}$ Luis Rojas cita el testimonio de un jefe nacional del Trabajo Militar de Masas del PC: "donde mayor resistencia encontró para incorporar las nuevas formas de combate proclamadas por el PC, fue en los dirigentes sindicales (...) era donde mayor arraigo tenía la idea de que las acciones de masas no podían ser armadas ni de un carácter violento ajenas a las luchas tradicionales de la clase obrera", Luis Rojas, De la rebelión popular a la sublevación imagina. Antecedentes de la Historia Política y Militar del Partido Comunista de Chile y del FPMR 1973-1990, Santiago, Lom ediciones, 2011, p. 31.

29 Rolando Álvarez Vallejos, Arriba los pobres del mundo. Cultura e identidad política del Partido Comunista de Chile entre democracia y dictadura. 1965-1990, Santiago, Lom ediciones, 2011, p. 12.

${ }^{30}$ Rolando Álvarez, Desde las sombras. Una historia de la clandestinidad comunista (1973-1980), Santiago, Lom ediciones, 2003, pp. 63-64.
} 
sindicalismo estaba mucho más anclada en la cultura política comunista. El llamado "recabarrenismo" 31 tenía en el mundo sindical a su nicho más propio, por lo que la implementación de estas nuevas formas se realizó con una mezcla de buenas intenciones, espontaneísmo y principalmente "pragmatismo", manifestado en la "preocupación por resolver problemas domésticos o prácticos de las personas, en ocupar espacios legales cuando los hubiera" 32 o ilegales si las condiciones lo ameritaban.

Lo que llama la atención aquí, no es entender cómo la PRPM se tradujo en el sindicalismo donde el PC tenía influencia - en particular en los docentes -, sino comprender la tensión generada por la implementación de esta línea en los profesores comunistas, la cual al no tener mayores rangos de acción, por ser el ámbito sindical predominantemente público y carente de una tradición rupturista, generó posiciones ambivalentes.

Aquí planteamos que en general los profesores comunistas intentaron desarrollar - dentro de sus condiciones de posibilidad - una política sindical coherente con la PRPM, donde se tuvo la intensión de tender hacia la radicalización con formas específicas, con docentes movilizados y dispuestos a paralizar sus funciones cuando otros sectores pasaran adelante, aprovechando la masividad del profesorado y su presencia nacional. Sin embargo, la manera en que esto se intentó no fue unidireccional.

Uno de los principales representantes de una de las líneas de desarrollo, Jorge Pavez, señala sobre la PRPM que "me pareció una política justa, pero es evidente que más de un desajuste con la realidad se sufría entre los que vivían sumergidos en la más completa clandestinidad por el trabajo militar, el aparato de dirección clandestino del Partido, y la gente como nosotros (...) que actuábamos con nuestra propia identidad $\mathrm{y}$ a rostro descubierto"33. Mientras que Guillermo Scherping recuerda que en el profesorado comunista la PRPM significó: "mucho debate. A veces no un debate explícito, pero en general en ese debate predominaba la decisión política. Incluso los que no estaban suficientemente convencidos, asumían que la lectura de la realidad era esa. Y aunque gustara o no, hubiese disposición o no de ir hasta el final, era la política que correspondía" 34 .

De esta manera, estos dirigentes trataron de amalgamar en las organizaciones de trabajadores la lucha de masas con formas más radicales de lucha. El resultado de esto será

\footnotetext{
${ }^{31}$ Rolando Álvarez, "La herencia de Recabarren en el Partido Comunista de Chile. Visiones comparadas de un heredero y un camarada del "Maestro". Los casos de Orlando Millas y Salvador Barra Woll", en Rolando Álvarez, Augusto Samaniego y Hernán Venegas (editores), Fragmentos de una historia. El Partido Comunista de Chile en el siglo XX. Democratización, clandestinidad y rebelión (1912-1994), Santiago, ICAL, 2008.

32 Álvarez, Arriba los pobres del mundo..., op.cit., p. 193.

${ }^{33}$ Jorge Pavez Urrutia, Un hombre en la multitud. Recuerdos de un luchador social, Santiago, Das Kapital Ediciones, 2010, p. 107.

${ }^{34}$ Entrevista del autor a Guillermo Scherping, 25 de enero de 2016. Scherping fue dirigente comunal de Viña del Mar de la AGECH y también dirigente nacional de esta organización.
} 
desigual, pero expresaba de diversas formas esa "combinación y síntesis entre las tradiciones y las nuevas incorporaciones de método y formas de lucha",35.

Sin embargo, ni en el movimiento sindical en general ni en específico en las organizaciones de profesores, la participación de los militantes comunistas fue homogénea, cuestión pocas veces vista en la historia de este Partido, caracterizada por su disciplina y su "mandato sacrificial" 36 . A nuestro entender, estas diversas posiciones se debieron al debate interno que se estaba dando en el PC respecto a la manera de implementar la PRPM, como también por las condiciones propias de la clandestinidad que vivió este partido durante los 17 años de dictadura militar.

Es por esto que dentro de los profesores, quienes apostaron por levantar una organización de educadores abiertamente opositora a la dictadura fueron aquellos docentes que optaron por "una" forma de entender la PRPM, apuesta nada de sencilla en condiciones de ejercer un empleo altamente público y una militancia clandestina. Mientras que otros docentes comunistas con un discurso mucho más sindical en un inicio, tuvieron "otra" forma de entender la PRPM más ligada a las amplias masas, y terminaron participando en una organización creada por la dictadura, donde se encontraba la mayoría silenciosa del profesorado, incluidos quienes apoyaban acérrimamente al régimen dictatorial.

\section{El debate interno de los docentes comunistas respecto a la orgánica sindical}

La presencia comunista en el magisterio tuvo un reimpulso a fines de los años 70, propiciado principalmente por jóvenes docentes. Ya en los primeros años de los 80, ese reimpulso se fue traduciendo en organización, ya sea de profesores que tenían una cierta experiencia en educación, pero que no habían ejercido labores sindicales o que recién comenzaban su trabajo en las escuelas y se transformaban en dirigentes.

Rápidamente, en el seno del magisterio comunista se comenzaron a experimentar dos tendencias respecto a la táctica organizativa. Por un lado, estaban los ex dirigentes del SUTE -que eran quienes conducían la línea del PC en el profesorado-, los que primeramente a fines de los 70 buscaron revivir esa organización ${ }^{37}$. Ante los nulos resultados de esta iniciativa modificaron su táctica, y a partir de 1982 aproximadamente buscaron "rescatar el CdP desde dentro".

Por otro lado, el grupo de profesores jóvenes era reacio a reconstituir el SUTE y propiciaron instancias menos ambiciosas, lo que se tradujo en que a inicios de 1981 desde la CME y las otras instancias regionales mencionadas, se diera origen al "Movimiento de

\footnotetext{
${ }^{35}$ Rolando Álvarez, "Las Juventudes Comunistas de Chile y el movimiento estudiantil secundario: un caso de radicalización política de masas (1983-1988)", en Rolando Álvarez y Manuel Loyola (editores), Un trébol de cuatro hojas. Las Juventudes Comunistas de Chile en el siglo XX, Santiago, Ariadna Ediciones, 2014, p. 172.

${ }^{36}$ Manuel Loyola, «El mandato sacrificial y la cultura política del comunismo chileno», Izquierdas, Año 1, Número 1, julio 2008.

${ }^{37}$ La mayoría de estos ex dirigentes se encontraba fuera de la docencia, ya sea por haber sido exonerados o porque el reconocimiento público de su militancia le negaba el acceso al cargo por parte de las autoridades.
} 
Participación Gremial", el cual estaba compuesto principalmente por profesores del MAPU, PS-Almeyda y PC (siendo estos últimos la mayoría). Este "Movimiento" se entendía como una organización de hecho, sin amparo jurídico y que a lo sumo pretendía constituirse en una corriente de opinión al interior del CdP. Sin embargo, desde su nacimiento no descartaron emprender el camino paralelo: "no se trata de una organización paralela al Colegio - explicaron dirigentes de la Coordinadora Metropolitana - sino que surge al interior de éste, para buscar y promover mecanismos para una más efectiva participación" ${ }^{38}$, aunque dejaban en claro que si el CdP "a través de su nuevo ordenamiento normativo no permite una efectiva canalización de los intereses reales del magisterio, con la necesaria participación de los maestros en las discusiones, se haría necesaria la creación de otro organismo que sí lo hiciere" 39 .

El rechazo de los jóvenes a revivir el SUTE, lo justifican porque la idea de constituir sindicatos dentro del Plan Laboral significaba levantar organizaciones demasiado pequeñas, limitadas a la empresa (colegios subvencionados o municipios, en este caso), las que fácilmente podían ser desarticuladas por los empleadores y que además fomentaría la atomización, "no porque no nos pareciera importante una organización de carácter sindical para el magisterio, sino fundamentalmente porque no lo veíamos viable" 40 . Por esto se pensó en constituir una organización que permitiera la posibilidad de tener un alcance nacional, independiente de que no fuese tan masiva, pero que la conformación les permitiera la capacidad de representar a los docentes a nivel nacional.

Sin embargo, la táctica de levantar este "Movimiento" como una corriente al interior del CdP también varió pragmáticamente cuando la legalidad de la dictadura permitió generar más de una entidad gremial. Desde 1981 los Colegios profesionales pasaron a ser simples asociaciones gremiales y eso permitió la existencia de múltiples asociaciones de este tipo. Allí, este grupo buscó un camino paralelo, descartando la idea de generar una corriente crítica al interior del CdP, lo que implicó que "las divergencias con el aparato interno del Partido comenzaron a manifestarse" 41 .

En cambio, el traspaso de la administración de los establecimientos públicos a las municipalidades, reforzó la idea de la conducción del ECM respecto de las posibilidades de revivir el SUTE, "reflotaba las propuestas que particularmente levantaba Julio González, tratando de influir en el resto de los integrantes de CEA, que argumentaban que ahora más que nunca era perfectamente viable la resurrección del SUTE a partir de la creación de sindicatos por municipios que confluyeran finalmente en una gran confederación"42.

\footnotetext{
38 «Profesores: tras caminos de participación», Solidaridad, segunda quincena de agosto $1981, \mathrm{n}^{\circ} 118$, año 6 , p. 9.

${ }^{39}$ Idem.

${ }^{40}$ Pavez, op.cit., p. 87.

${ }^{41}$ Idem.

${ }^{42}$ Ibid., p. 90. El primer sindicato de trabajadores de la educación municipal recién se conformó en agosto de 1985, en la comuna de La Florida, donde varios militantes comunistas tuvieron una importante participación como Natacha Poblete, Bernardo Medel y Eterlinda Bravo.
} 
Debido a que estas posibilidades nunca se materializaron, este sector de profesores comunistas a la larga se mantendría dentro del CdP.

En cambio, rápidamente el "Movimiento" optó por la vía del camino propio y decidieron conformar la Asociación Gremial de Educadores de Chile (AGECH) ${ }^{43}$. Definitivamente, ambas posiciones no vislumbraban una táctica común.

Esta participación paralela de los militantes comunistas es un hecho atípico en la historia del PC, historia que se ha caracterizado además de su disciplina militante, por su actuar unido y bajo una línea política definida, lo que no da pie para dobles lecturas. A nuestro entender, el pragmatismo de actuar según cuál de las dos alternativas tuviera mejores resultados $^{44}$, se vio reforzado - como ya hemos mencionado- por las dificultades para asumir en el mundo sindical la PRPM.

Así, los jóvenes docentes comunistas, entusiasmados por la audacia y combatividad expresada en la PRPM, buscaron levantar una organización paralela que se planteara decididamente como opositora a la dictadura, mientras que los militantes más antiguos reconocían que se debía adoptar un discurso combativo, pero cada vez más fueron tomando posiciones conservadoras, limitándose a la institucionalidad vigente que representaba el $\mathrm{CdP}$, puesto que desde ahí podían adoptar un carácter de masas.

Al respecto, Jorge Pavez ${ }^{45}$ recuerda que "tuvimos que luchar primero contra nuestros respectivos partidos"46, testimonio que también entrega Fernando Azula, militante del PSAlmeyda: "no fue fácil. Hubo una gran discusión al interior de los partidos políticos de izquierda. El tema era cómo pasar de la vida clandestina al mundo público" "47. Esto debido a que levantar esta organización, decididamente opositora significaba visibilizar a algunos de los cuadros partidarios, los que en su mayoría era militantes jóvenes, sin gran experiencia y sin grandes responsabilidades orgánicas.

Como ya hemos mencionado, el ECM estaba liderado por antiguos dirigentes del SUTE ${ }^{48}$, los que se opondrán primeramente a la formación de la $\mathrm{AGECH}$, puesto que "estos

\footnotetext{
${ }^{43}$ Mayoritariamente los afiliados a la AGECH correspondieron a militantes de partidos políticos de oposición, en especial del PC y del PS-Almeyda; en menor medida militantes DC y MAPU, y muy marginalmente radicales y miristas.

${ }^{44}$ A la categoría de "pragmatismo" no le asignamos un carácter necesariamente peyorativo, sino que ligado a su expresión etimológica de otorgarle mayor importancia a las cosas prácticas y los resultados, siendo flexible y realista.

${ }^{45}$ Dirigente de la CME, de la AGECH y, una vez disuelta ésta, del CdP.

${ }^{46}$ Entrevista a Jorge Pavez en Cuevas, op.cit., p. 86.

${ }^{47}$ Entrevista en Andrés Figueroa Cornejo, La Asociación Gremial de Educadores de Chile, AGECH: Los profesores por la democracia y la dignificación de la profesión, Trabajo para optar al Título de Periodista, Santiago, Universidad de Santiago de Chile, 2002, p. 24.

${ }^{48}$ Es necesario hacer la salvedad que las diferentes posiciones no se debieron exclusivamente a una cuestión generacional. Casos que permiten falsear la tesis generacional la encontramos en las figuras de César Godoy y Jaime Gajardo. El primero era un antiguo dirigente comunista del magisterio que volvió del exilio en 1984 y falleció al año siguiente. Durante este corto periodo se dedicó a asesorar y apoyar a la AGECH en lo que más
} 
compañeros estimaban de que no, que eso era muy socialdemócrata y que además era paralelismo sindical, porque el Colegio existía, y nosotros decíamos, si el Colegio existe pero no desde los profesores, tiene dirigentes designados, está intervenido, no hay organización del magisterio. Entonces no estamos haciendo paralelismo con nadie" ${ }^{, 49}$.

Previo a la fundación de la AGECH a fines de noviembre de 1981, el intenso debate de los profesores comunistas se materializó en un encuentro - realizado en condiciones de clandestinidad, en el distinguido colegio Verbo Divino-, entre los dirigentes de la CME y los viejos cuadros sindicales. Allí se perfilaron dos claras posiciones: la que definía el PC oficialmente mediante el ECM que buscaba "dar una lucha frontal desde el magisterio para frenar los cambios, intentando paralelamente reorganizar el SUTE desde la base-escuela (...) hablaban como si aún estuviéramos en la UP y parecían no percatarse de que desarrollábamos un encuentro clandestino" "50. Mientras que los jóvenes profesores, menos grandilocuentes, buscaban paso a paso ir organizando a las diversas experiencias críticas y opositoras surgidas en el país.

Esta posición fue reforzada cuando las organizaciones internacionales de profesores que enviaban recursos para la reorganización docente opositora a la dictadura, se enteraron que existía la CME, por lo que desde ese momento se les reconoció "como organización legítima, y si bien se valoraba el rol y el papel que podían cumplir los ex dirigentes del SUTE, el hecho de no estar en actividad implicaba que el vínculo formal se mantendría con nosotros" $"$.

Finalmente, la disputa al interior del ECM sería ganada por los profesores más jóvenes con Carlos Mena y Jorge Pavez a la cabeza (ambos dirigente de la CME que habían sido integrados recientemente al ECM), desechándose la posibilidad de reorganizar el SUTE. Según el testimonio de Jorge Pavez, esta primera batalla fue zanjada en una reunión clandestina en la casa de éste, donde estuvieron presentes Julio González, Ramón Meneses, Jorge Pavez, Carlos Mena, Carlos Sierra y un personaje que el anfitrión no conocía, el que al parecer era un funcionario del partido. González comenzó leyendo un documento que era la opinión directa del Partido, donde se favorecía la posición de los ex dirigentes y se desechaba la idea de constituir la $\mathrm{AGECH}^{52}$. Sin embargo, Mena y Pavez batallaron duro para revertir la situación, la cual desniveló la balanza hacia los jóvenes profesores cuando Carlos Sierra comenzó tibiamente a respaldar las posiciones del camino propio ${ }^{53}$.

pudo. Gajardo, joven profesor a inicios de los 80, estuvo siempre en el CdP y al alero de CEA (una organización de fachada, financiada con recursos internacionales). Otro ejemplo de un antiguo dirigente del SUTE que apoyó a la AGECH fue el de Nicolás Ruiz, Véase, Departamento de Profesores Jubilados de San Miguel, «En memoria de Nicolás Ruiz Fuentealba», El Siglo, Santiago, no 1030, 6 de abril de 2001, p. 22.

${ }^{49}$ Entrevista del autor a Guillermo Scherping, 25 de enero de 2016.

${ }^{50}$ Pavez, op.cit., p. 87.

${ }^{51}$ Ibid., p. 88.

${ }^{52}$ Ibid., p. 95.

${ }^{53}$ Ibid., p. 96. 
De esta manera, los jóvenes lograron que el PC diera el visto bueno para la fundación de la AGECH, sin el cual ésta no se habría constituido, ya que los demás partidos que la respaldaban (PS-Almeyda, MAPU-OC y MIR) no tenían la capacidad de despliegue que aseguraban los militantes comunistas. Sin embargo, este visto bueno del Partido no fue una orden partidaria para toda la militancia, sino que más bien fue una autorización para que los docentes comunistas que estaban siendo partícipes de este proceso de radicalización gremial a lo largo de todo el país se sumaran activamente a la construcción de lo que sería la AGECH. Esto permitió que otros docentes comunistas continuaran afiliados exclusivamente al CdP y que la posición que había perdido esta batalla volviera a resurgir con el tiempo. Ante esto, Julio González participará en la constitución de la AGECH, para luego ir cambiando su posición desde un discurso confrontacional a uno pragmáticoconservador de insertarse en la institucionalidad que representaba el $\mathrm{CdP}^{54}$.

\section{La vía de la oposición frontal}

Con la fundación de la AGECH, estos jóvenes comunistas lograron junto a otros militantes de izquierda desarrollar una suerte de "sindicalismo de vanguardia", donde las acciones de sus dirigentes lograban "romper el cerco de la escuela (...) en oposición al designió [sic] de gobierno que era la de controlar la función docente a través de un ente creado por el mismo: El Colegio de Profesores"55. Sus prácticas fueron desafiantes frente a las autoridades de la dictadura y llevadas a cabo principalmente por militantes de organizaciones políticas, lo que permitió que la $\mathrm{AGECH}$ rápidamente se dotara de una estructura nacional ${ }^{56}$. Esa audacia, hizo a esta organización no crecer desmesuradamente (a pesar de llegar a tener 10 mil asociados), pero sí ganar un prestigio frente a las masas, obteniendo legitimidad para su lucha y la de otros sectores, por lo que cuando los docentes aumentan sus niveles de luchas, en los años 86-87, la AGECH continuó con su crecimiento a pesar de que varias organizaciones políticas comenzaban a quitar el respaldo a las posiciones más confrontacionales y a la movilización social.

En este sentido, nos parece que la posición de quienes planteaban revivir el SUTE no es que haya sido menos confrontacional que la de los jóvenes comunistas, sino que seguía anclada en la manera histórica cómo los comunistas han entendido el trabajo de masas, es decir, una forma mucho más expuesta y abierta, considerando que la legalidad del sindicato permitirá hacer un trabajo de masas amplio; en cambio la propuesta de los jóvenes era que

\footnotetext{
${ }^{54}$ De la misma forma, los profesores comunistas de la AGECH irían hegemonizando su presencia en el ECM. A los nombres de Pavez y Carlos Mena incluidos en 1981, se incorporan a este ECM en 1983: Manuel Guerrero, Guillermo Scherping (a la fecha miembro del Comité Central de las Juventudes Comunistas) y Sofía Colodro, todos dirigentes de la AGECH.

55 Asociación Gremial de Educadores de Chile, Documento base de discusión gremial Cuarta Asamblea Nacional de AGECH (Julio 1985), pp. 6-7.

${ }^{56}$ Con sólo 3 años la AGECH daba cuenta de su actuar, "Hemos defendido los intereses más urgentes del profesorado y señalado acciones de presión más radical sobre las autoridades como fueron: el Ayuno Nacional, Ollas Comunes y Mitines de Cesantes, Marchas de Protesta, Paros Parciales y Manifestaciones en el Hall Central del Mineduc", Asociación Gremial de Educadores de Chile, Documento base de Discusión Gremial Cuarta Asamblea Nacional de AGECH, julio 1985, p. 7.
} 
las condiciones represivas no permitirían aquello. Éstos decían que había que trabajar con las bases - como lo venían haciendo-, pero que se requería de un número de cuadros dispuestos a dar la cara por esas bases, de otra manera éstas no se sentirían representados por ellos, debían ser la avanzada del pueblo. Estas prácticas sindicales fueron llevadas a cabo mediante denuncias públicas, acciones de agitación, marchas, mitines, manifestaciones, ayunos, participación activa en las jornadas de protesta nacional, etc. Prácticas que trajeron consigo la represión, amedrentamiento, relegaciones de numerosos dirigentes locales, asaltos de las sedes sindicales, etc.

Por eso, independiente de que el CdP tenía miles de asociados, la AGECH lograría tener un mayor poder de convocatoria, que se lograba a partir de la disciplina de los militantes orgánicos y la vinculación con el mundo popular ${ }^{57}$. De esta manera, hechos como el "Caupolicanazo" de abril de 1983, fueron más allá que simples actividades gremiales, siendo seguidas por el conjunto de la oposición a la dictadura; en esa ocasión, asistieron también sectores anexos al magisterio, los cuales estaban a la expectativa de que algún sector tomara la iniciativa para manifestarse en contra del régimen ${ }^{58}$. Fernando Azula recuerda que "esta situación alentó con mucha fuerza la línea al interior de la organización que planteaba una mayor radicalización y politización de la Agech, en desmedro del trabajo más bien gremial"59.

Este carácter audaz y político, necesariamente trajo consigo la represión dictatorial, cuestión que tuvo su hecho más duro con el degollamiento del dirigente metropolitano de la AGECH e importante dirigente comunista Manuel Guerrero Ceballos, en marzo de 1985. Para muchos, estas acciones represivas implicarían el aislamiento de la AGECH de las masas, por el temor que suscitarían, sin embargo el despliegue orgánico de los militantes permitió que se siguiera creciendo en afiliación, a pesar de las relegaciones de dirigentes provinciales, el encarcelamiento de sus dirigentes nacionales, el allanamiento de sus sedes o las exoneraciones de sus bases de asociados.

Manuel Guerrero ${ }^{60}$ y otros dirigentes, son considerados como representativos de esta posición dentro de los profesores comunistas, "encarnaban la nueva generación de comunistas cuya influencia en el seno de las diferentes organizaciones sociales parecía

\footnotetext{
${ }^{57}$ Como he mencionado, en la AGECH los comunistas fueron fundamentales, pero no los únicos militantes. Cabría la tarea de estudiar la importante participación del sector "Almeyda" del PS, de los pocos socialistas del sector "comandantes" y miristas como para dar una visión más clara de la participación de las organizaciones de izquierda. La presencia del PC en la AGECH se acrecentaba al estar en la conducción no sólo a nivel nacional con la figura de Pavez, sino que también en los regionales más grandes del país, con Guillermo Gac en Valparaíso, Olimpia Riveros en Concepción y Manuel Guerrero en el Metropolitano.

${ }^{58}$ En esa ocasión, "se corrió la voz de que los profes sacarían del teatro una gran marcha contra Pinochet. De mi zona fuimos un buen número de personas", testimonio de Daniel Miranda, dirigente de los trabajadores desempleados de Lo Espejo, en Figueroa, op.cit., p. 31.

${ }^{59}$ Idem.

${ }^{60}$ Regresó al país tras su exilio a fines de 1982 y rápidamente se integró a la AGECH, siendo dirigente del Departamento de profesores Cesantes en primera instancia, y luego presidente del regional Metropolitano de la $\mathrm{AGECH}$.
} 
incrementarse. Para la dictadura eran, en suma, peligros potenciales y blancos preferidos"61. Guerrero fue uno de los profesores con más altas responsabilidades partidarias que se sumó activamente a la AGECH, desarrollando un estilo de liderazgo en el magisterio muy en sintonía con la PRPM, al conducir acciones mucho más confrontacionales como marchas, mítines, denuncias y declaraciones ${ }^{62}$. De la misma forma, Guerrero fue uno de los promotores en el magisterio de prácticas sindicales comunes en el movimiento obrero, como la organización de los docentes cesantes y la implementación de "ollas comunes". Scherping explica que esto se desarrolló más desde el regional metropolitano que desde la AGECH a nivel nacional, puesto que en el metropolitano la conducción comunista era más hegemónica, mientras que "en el debate nacional de la AGECH y en la pluralidad que tenía la dirección de la AGECH predominaban más ideas de centro de la Política Rebelión, más que ideas de la Política de Rebelión propiamente tal"63.

La posición de Guerrero inclusive llegó a plantear que si la dictadura le quitaba la legalidad jurídica a la AGECH —cuestión que sucedió por unos meses en 1983-, se debía "continuar sin amparo jurídico el trabajo político y gremial" ${ }^{64}$. En cierto sentido, esta postura de Guerrero inclusive representó una disputa al interior de la posición paralelista de los comunistas de la AGECH, puesto que a diferencia de Pavez, Guerrero planteaba que "debíamos olvidarnos de recuperar la personalidad jurídica, que bastaba con mantenernos como entidad de hecho" ${ }^{\circ 5}$, posición que fue seguida por otros docentes comunistas como Guillermo Scherping y Sofía Colodro.

En definitiva, esta posición dentro de los profesores comunistas fue dando sus frutos y se impregnó a nivel discursivo, adoptando posiciones más confrontacionales. Así por ejemplo, frente a la detención de Pavez tras el paro nacional del 3 y 4 de septiembre de 1985, el líder de la AGECH emitió el siguiente mensaje desde la cárcel:

El pueblo tiene la palabra. Todos deben asumir su responsabilidad en esta hora de definiciones, ahora sólo cabe movilizarse y actuar. Los discursos y las palabras no sirven. Sólo la lucha, y la unidad gestada en esta lucha, hará que podamos vivir en un Chile distinto. Estoy convencido de que ni la cárcel ni la represión, ni los asesinatos conseguirán detener la lucha del pueblo chileno por conseguir un futuro libre y democrático ${ }^{66}$

Mientras que frente a esta misma detención otros profesores comunistas de la AGECH llamaron "al profesorado, manifiesten su repudio a la persecución que sufre el magisterio

\footnotetext{
${ }^{61}$ Patrick Guillaudat y Pierre Mouterde, Los movimientos sociales en Chile: 1973-1993, Santiago, Lom ediciones, 1998, p. 167.

${ }^{62}$ La posición de Guerrero respecto a la PRPM fue variando. En el debate interno previo (fines de los '70), fue bastante reticente a la adopción de "todas las formas de lucha", pero una vez en Chile se abocó de lleno a su implementación y desarrollo.

${ }^{63}$ Entrevista del autor a Guillermo Scherping, 25 de enero de 2016.

${ }^{64}$ Figueroa, op.cit., p. 12.

${ }^{65}$ Pavez, op.cit., p. 99.

66 “Desde la cárcel: Una sola voz", Análisis, n 111, año VIII, 8 de octubre de 1985, p. 11.
} 


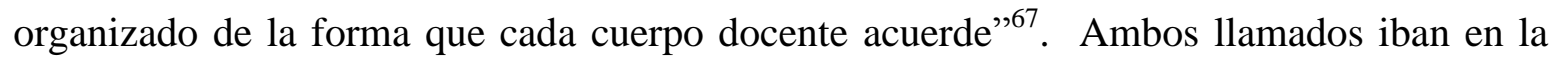
línea de no descartar ninguna forma de lucha, que si bien no mencionaban explícitamente las formas más radicalizadas, al menos desde el magisterio dejaban abierta su posibilidad, a diferencia de docentes de otros sectores como la DC o de la renovación socialista, que de plano descartaban las formas radicalizadas.

Olimpia Riveros, dirigenta comunista de la AGECH de Concepción recuerda el rol jugado dentro de la PRPM: "Para nosotros la Rebelión Popular fue radicalizar las protestas, en nuestra participación particular. Y como organización fue más bien permitir. Nosotros no encabezamos digamos una cuestión más cotota, pero facilitamos; fuimos manto, fuimos

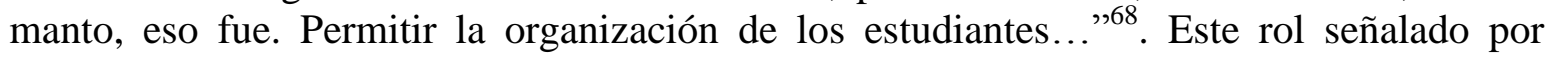
Riveros hace mención a que desde la AGECH los militantes comunistas fueron la cara visible de las jornadas de protesta a nivel nacional, siendo quienes en muchas ocasiones hacían los llamados a marchas y jornadas de protestas, como también fueron los articuladores principales de organismos locales del Comando Nacional de Trabajadores ${ }^{69}$. La fuerte articulación con el movimiento estudiantil secundario especialmente en las luchas contra la municipalización del año 1986, al igual que los vínculos con las familias de los estudiantes, especialmente donde existían cercanías con los sectores opositores como los liceos emblemáticos (Liceo de Aplicación en Santiago, Liceo Lorenzo Arenas y Enrique Molina en Concepción) o las escuelas ubicadas en barrios populares (La Granja, Pudahuel, Conchalí, San Miguel, Coronel, Lota, Talcahuano, etc.), representaron herramientas vitales para la masificación de la radicalización de la política comunista.

El profesor Alejandro Sepúlveda, dirigente comunal de Talcahuano de la AGECH entrega un testimonio en una línea similar, señalando que el carácter opositor de esta organización permitió dotar a la PRPM de un carácter de masas a esa política, debido a "la transversalidad que tiene el magisterio nacional" y su presencia a lo largo de todo el país ${ }^{70}$.

Sin embargo, el convencimiento de la táctica de la movilización popular sufrió algunos traspiés con los sucesos del año 1986 (caracterizado como "el año decisivo" para derrocar a la dictadura), situación que fue aprovechada por los sectores que eran críticos de la movilización y de las acciones callejeras, como también por los sectores comunistas que siempre fueron críticos de la PRPM. Iván Ljubetic ${ }^{71}$, representante de esta última posición, señala que los hechos de 1986 dañaron de manera significativa la imagen de la izquierda, lo que sumado a la exclusión y diferenciación que hacen los partidos de centro-izquierda respecto a estas prácticas "generó evidentes disidencias y discrepancias entre el profesorado de izquierda y, de manera clara, desconfianza entre la gente por la conducta política de sus

\footnotetext{
${ }^{67}$ «La AGECH criticó detención de sus dirigentes y censo al profesorado», Las Últimas Noticias, Santiago, 2 de octubre de 1985 , p. 4.

${ }^{68}$ Entrevista del autor a Olimpia Riveros, 28 de julio de 2016.

${ }^{69}$ El CNT fue una organización multisindical opositora al régimen de Pinochet, nacida en 1983 y disuelta en 1988 al conformarse la Central Unitaria de Trabajadores.

${ }^{70}$ Entrevista del autor a Alejandro Sepúlveda, 28 de julio de 2016.

${ }^{71}$ Historiador comunista, ex presidente del Consejo Provincial Cautín de la FEDECH en la segunda mitad de los 60 y consejero nacional del SUTE. Estuvo exiliado en la RFA y retornó a Chile en octubre de 1990.
} 
militantes"72. La manifestación más clara de esto, fue el ascenso de la presencia de los sectores DC en el magisterio por una parte (ganando la conducción nacional y los principales regionales del $\mathrm{CdP})^{73}$, y la pérdida del respaldo al camino paralelo de la AGECH que habrían brindado los partidos políticos, a pesar de que a nivel de bases la AGECH continuaba con su crecimiento y desarrollando un importante proceso de movilización contra la municipalización de la educación.

Ese mismo año 1986, las movilizaciones docentes aumentaron su masividad, debido principalmente a que el proceso de municipalización de la educación llevado a cabo por la dictadura comenzaba a llegar a su fin con el traspaso de los establecimientos emblemáticos de la capital, donde el movimiento secundario tenía su mayor fuerza. Fue por eso que el CdP (conducido ahora por la DC) y la AGECH comenzaron ese año a realizar coordinaciones para enfrentar de manera conjunta la municipalización, pero donde los profesores agechinos daban cuenta de una mayor experiencia movilizadora, logrando sortear con su voluntad de lucha la menor cantidad de asociados frente al CdP. Ante esto comienza a surgir en la dirigencia, y no en las bases, la idea de autodisolver la AGECH para fusionarse con el $\mathrm{CdP}^{74}$.

El profesor comunista Bernardo Medel, recuerda: "la posibilidad era que la gente, que la dirigencia de la AGECH pasará a integrar las organizaciones del Colegio y eso fue resistido, porque mucha gente no estaba de acuerdo, porque consideraban que la AGECH era un verdadero centro de lucha, de creatividad, de ideas" ${ }^{, 75}$. Una opinión similar entrega Olimpia Riveros al describir la asamblea que se realizó en Concepción donde se comunicó la decisión de autodisolver la AGECH:

la inmensa mayoría estábamos en contra, por lo que la autodisolución para entrar al Colegio de Profesores la hicimos con mucha desconfianza (...) porque yo me compré la Rebelión Popular al tiro, pensando qué hacemos, cómo lo hacemos, cómo apoyamos. Porque como éramos profes no podíamos meternos a la cosa armada directamente, pero podíamos ser cobertura pa' cuanta gente quisiera hacer $\operatorname{cosas}^{76}$.

\footnotetext{
${ }^{72}$ Iván Ljubetic, Historia del magisterio chileno, Ediciones Colegio de Profesores de Chile A.G., Santiago, 2003, p. 258. Sobre los hechos del año 1986 se refiere al atentado fallido a Augusto Pinochet y a la masiva internación de armas, ambas acciones realizadas por el Frente Patriótico Manuel Rodríguez (FPMR) aparato armado del PC.

${ }^{73}$ En la elección del CdP de 1985 la DC obtuvo 20.213 votos, representando al 29,1\%; en 1987: 22.494 votos que corresponde al 35,3\% y en 198926.010 votos, creciendo al 40,2\%. Cox, op.cit., p. 25.

${ }^{74}$ Figueroa plantea que la municipalización "lesionó las condiciones laborales de los docentes y redundó en el fortalecimiento de la Agech, debido al gran descontento producido", op.cit., p. 10.

${ }^{75}$ Entrevista del autor a Bernardo Medel, 15 de marzo de 2016. Bernardo Medel, profesor de enseñanza básica, fue miembro de la AGECH y dirigente del sindicato de profesores de la comuna de La Florida a fines de los 80. Las resistencias declaradas por Medel a la autodisolución son reconocidas a pesar de que su posición en esa coyuntura fue positiva ante la decisión del ingreso al CdP.

${ }^{76}$ Entrevista del autor a Olimpia Riveros, 28 de julio de 2016.
} 
En este debate se impuso la idea del "país real", el cual no estaría en la AGECH y si en el $\mathrm{CdP}$, puesto que en aquella estaban los profesores más politizados, siendo una organización de cuadros de la izquierda (los más audaces e ilustrados ${ }^{77}$ ), mientras que el CdP era una organización de masas no politizadas, donde la DC tenía una amplia presencia, al igual que los sectores que apoyaban a la dictadura.

Más que desde las bases del magisterio, fue a partir de los acuerdos partidarios entre socialistas y comunistas principalmente, donde se decidió la autodisolución de la AGECH, a pesar de que las bases agechianas, en especial comunistas y miristas, se oponía a esta decisión:

Fue muy doloroso porque habían sectores que la rechazaban de plano (...) El MIR fundamentalmente, Alberto Carrasco alegando, "nooooo, cómo se van a entregar a esa organización fundada por Pinochet". Y los comunistas todos disciplinados ahí, "bueno, ya sî”. Había una cosa en Santiago que se llamaba "Comité de enlace", donde estaba Ramón Meneses, y ellos habían instruido de alguna manera qué era lo que había que hacer, debe de haber habido algún acuerdo político no sé con quién. La cosa es que venía la propuesta de que nos disolviéramos y fuéramos a las elecciones. Nosotros lo hicimos, pero nunca estuvimos convencidos de que fuera lo correcto ${ }^{78}$.

Para Iván Ljubetic, el dilema que surgió “especialmente en el seno de los comunistas, era mantener una organización de clara orientación progresista y de clase o incorporarse a otra, controlada por elementos partidarios de la dictadura y en la que, en ningún caso, los maestros más consecuentemente democráticos dejarían de ser -en el corto y mediano plazo- minoría"79. De esta manera emergieron estas dos posiciones, por un lado quienes veían en el CdP una posibilidad para revitalizar una organización de tipo gremial que contaba con miles de afiliados, mientras que por otro lado estaban quienes buscaban una organización que iba más allá de lo puramente gremial, apuntando a una lucha política. En este sentido, los profesores comunistas representaron la única militancia partidaria donde se suscitó este debate, el cual era correlato de fuertes debates internos del PC.

El resto de las militancias partidarias al interior de la AGECH prácticamente no experimentaron debate alguno; la posición de los profesores DC agechinos fue la de abandonar esta organización para ingresar al $\mathrm{CdP}$ sin esperar a la decisión de la autodisolución, ni la opinión de los demás sectores; los militantes del PR y del socialismo almeydista apoyaron la autodisolución sin reparos, mientras que la pequeña presencia del mirismo se resistió a ésta, sin posibilidad alguna de incidir en la decisión.

\footnotetext{
${ }^{77}$ Riveros en la mencionada entrevista, da cuenta del temor de algunos docentes comunistas a participar en la AGECH, debido al identificable carácter opositor de esta organización, lo que expresa que el solo hecho de pertenecer a la AGECH ya comprendía una acción más audaz y confrontacional.

${ }^{78}$ Idem.

${ }^{79}$ Ljubetic, op.cit., p. 244.
} 
Al interior del debate del profesorado comunista fueron las posiciones pragmáticas las que volvieron a ganar fuerza, puesto que la transición pactada con la dictadura hacia una democracia dentro de los límites impuestos por aquella, iba ganando mucho más terreno que la salida insurreccional propiciada por el PC, el MIR y un sector del PS (liderado por Clodomiro Almeyda) ${ }^{80}$. Por lo que, los jóvenes profesores comunistas que habían logrado ganar la batalla inicialmente, al aceptar el PC que participaran en la formación de una organización paralela, ahora debían a regañadientes bajar sus banderas rupturistas para entrar a competir dentro de la línea trazada por la dictadura, puesto que eso era lo más pragmático. Mantener la AGECH era insistir en la radicalización cuando la renovación de los demás partidos ya había adoptado un carácter centrípeto y no hacia la izquierda, lo que no significó que los pocos sectores que se resistieron a la renovación criticaran este pragmatismo político como una actitud oportunista, que así como le generaba avances, también fuertes críticas desde la izquierda.

\section{El pragmatismo comunista dentro de la institucionalidad}

Por otro lado, tal como hemos mencionado, hubo un grupo de profesores comunistas que permanecieron dentro del CdP, a pesar que desde fines de 1981 no era obligatorio estar afiliado a éste para ejercer la docencia. Este sector, correspondía a quienes hasta ese año habían sostenido que la tarea era revivir el SUTE, pero ahora comenzaron a cifrar sus mayores esfuerzos hacia el interior del CdP buscando democratizarlo, a sabiendas de que no era una organización sindical, pero que sí agrupaba a las masas, aunque fuese formalmente. Por esto se hicieron parte del "Comando por la Democratización del Colegio de Profesores", instancia constituida y liderada por los antiguos dirigentes del magisterio, de diversas organizaciones políticas, menos de la denomina "ultraizquierda". Así, el primer directorio de este "Comando" estuvo liderado por los democratacristianos Gastón Gilbert y Alfonso Bravo, por el PC Julio González ${ }^{81}$ y el radical Franklin Recabarren ${ }^{82}$.

Esta articulación opositora materializada en el "Comando" concentró sus esfuerzos en presionar a las autoridades para que llamasen a elecciones en el CdP. Sin embargo, cuando a comienzos de junio de 1984 oficialmente se organizaron elecciones, el "Comando" llamó a la abstención. La explicación que entregó Gilbert fue que: "los mecanismos imposibilitan que un dirigente no designado llegara a la directiva nacional. Sólo se renovaba el 40 por ciento de los cargos, y sólo las elecciones provinciales eran directas. Los dos tramos

\footnotetext{
${ }^{80}$ En 1987, este sector del socialismo también comenzaba a abandonar la vía insurreccional, por lo que otros sectores ya se habían disgregado de éste hacia la izquierda, como lo fue el PS-"Comandantes" y el PSSalvador Allende, además del Coordinador Nacional de Regionales (CNR). Solamente el primero de estos sectores tendría una pequeña presencia en el magisterio.

${ }^{81}$ González representó el mayor ejemplo de "pragmatismo", ya que como encargado del ECM inicialmente propiciaba revivir el SUTE, luego aparece conformando el Comando para la Democratización del CdP y en la misma fecha aparece en la lista de los 31 docentes que constituyeron la AGECH.

${ }^{82} \mathrm{El}$ único ausente de este grupo y que había participado de esta reorganización a fines de los '70 (“Comité de enlace") fue Carlos Eugenio Beca, militante del MAPU-OC que se vincularía luego más directamente con las instituciones académicas que con las organizaciones docentes.
} 
siguientes, regional y nacional, eran indirectos" ${ }^{\text {83 }}$. La abstención en esta elección fue del $87 \%$.

En diciembre de $1985^{84}$ se volvieron a realizar elecciones, ahora de manera directa en los cargos nacionales, regionales y provinciales, y el "Comando" decidió ahora participar activamente, sin embargo los sectores de la DC se negaron a conformar una lista única de la oposición, replicando en el mundo sindical la exclusión del PC en cuanto a su política de alianzas ${ }^{85}$. De esta manera, se estructuraron dos listas opositoras de acuerdo a los bloques políticos existentes. Una que agrupaba a los sectores de la Alianza Democrática ${ }^{86}$ y otra a los sectores de la "Intransigencia Democrática"87; esta última agrupaba a profesores socialistas del sector "Almeyda" e "Histórico", la Izquierda Cristiana, el MAPU y comunistas.

En este proceso electoral se reactivarían varios profesores comunistas que no participaron mayormente en la AGECH, como Pedro Valenzuela, Juan Carlos Llanos, el propio Carlos Sierra (integrante del ECM) y Jaime Gajardo. Desde acá buscaron reflotar el carácter reivindicativo de las organizaciones docentes y no tan político como el de la AGECH. Así lo expresó, Ramón Meneses:

la Intransigencia Democrática plantea como objetivo principal convertir al Colegio en una institución al servicio de los intereses de los maestros. Lograr una real participación de éstos en la elaboración de la política educacional. Propugnamos el derecho al escalafón y un sueldo base único para los profesores tanto fiscales, particulares como de establecimientos subvencionados ${ }^{88}$.

Aunque también reconocía la importancia de lucha antidictatorial, al señalar que "la democratización del Colegio es el paso previo, pero para ello debemos insertarnos en la

\footnotetext{
83 "Profesores: Rechazo a la democracia", Análisis, n 84, año VII, 19 de junio de 1984, p. 34.

${ }^{84}$ Este año vuelve del exilio el profesor radical Héctor Elgueta, quien había sido dirigente de la Sociedad Nacional de Profesores, la Federación de Educadores de Chile y del SUTE, y a su regreso pasó a ser el nuevo líder de este "Comando".

${ }^{85}$ Quienes controlaban la estructura sindical de la DC a mediados de los 80 eran los sectores que rechazaban la alianza con sectores marxistas, a pesar de que la mayoría de sus dirigentes más reconocidos eran del sector más progresista que sí aceptaba dicha alianza (Manuel Bustos, Rodolfo Seguel y José Ruiz Di Giorgio). En el magisterio, las principales figuras DC también eran de este último sector.

${ }^{86}$ Los candidatos nacionales de esta lista representaban a la DC, al Partido Social Demócrata, PS-Briones y PR.

${ }^{87}$ Iniciativa nacida en abril de 1985 buscando constituir una instancia de unidad opositora a partir de individualidades que, aun teniendo militancias, actuaran sin representación partidaria, pero con acuerdo de los partidos, cuestión esta última que terminaría primando. Salvo en el CdP, la Intransigencia Democrática no tuvo mayores logros de articulación.

88 "Después de doce años: Cien mil profesores eligen directiva”, Análisis, Santiago, n ¹20, 10 de diciembre de 1985, p. 11.
} 
lucha global del país. Porque jamás en los marcos de la Dictadura vamos a lograr una educación democrática, una organización democrática" ${ }^{\prime 89}$.

Los resultados de estas elecciones fueron sumamente positivos para la lista liderada por la DC y el socialismo renovado, obteniendo 3 de los 5 dirigentes nacionales, mientras que la lista pro-gobierno obtuvo solamente un cargo, al igual que la lista donde participaban los profesores comunistas; cargo que correspondió a Ramón Meneses, integrante del ECM y que obtuvo 3.720 votos representando al 5,4\%. De la misma forma, se destacó la obtención del PC de un cupo en el provincial Santiago del CdP, cargo ocupado por Jaime Gajardo ${ }^{90}$ y de un cargo en el regional Bío Bío por parte de Gorky Díaz.

El triunfo de Meneses se produjo a pesar de que quien encabezaba la lista fue Francisco Fuentes ("socialista histórico" con simpatías con el grupo "consenso", según su propia definición ${ }^{91}$ ) y que era secundado, además de Meneses, por Alberto Jaramillo Bórquez (Izquierda Cristiana), Alberto Galleguillos (PS-Almeyda) y Jorge Olivos (MAPU). Este triunfo reflejó la persistencia de numerosos profesores comunistas a nivel de base, especialmente en la región metropolitana, que fue donde más alta votación obtuvieron los dirigentes comunistas.

La conformación de este sector de profesores comunistas que buscó "rescatar el CdP" no debe ser identificado mecánicamente con los sectores al interior del PC reacios a la PRPM. Este sector representó la persistencia de las corrientes históricas del magisterio comunista que buscaron dotar de una impronta sindical a la organización de los docentes, sin embargo entendieron a ésta principalmente desde su orientación de masas más que desde una perspectiva confrontacional y opositora.

El triunfo de la oposición en el CdP, fue un aliciente para las posiciones pragmáticas de la mayoría de los partidos. Así por ejemplo, los escasos militantes de la DC que participaban en la AGECH reciben la orden partidaria de abandonar esa organización, tal como lo recuerda María Rozas, a la fecha dirigenta nacional de la AGECH y encargada de relaciones internacionales: "el partido [la DC] evaluó que ya estaban las condiciones para volcarse a trabajar dentro del Colegio: para nosotros la Asociación ya había cumplido su papel" "92. Esto reforzó el giro que comenzaba a dar hacia el centro político el magisterio socialista del sector Almeyda, como también sirvió a la rearticulación del socialismo renovado en el magisterio, el cual hasta mediados de la década había tenido escasa presencia.

De esta manera, ahora el CdP pasaba a ser comandado por la oposición, aunque con la hegemonía de una nueva alianza de "centro-izquierda" y no por el viejo tronco histórico de la izquierda que tuvo la hegemonía del movimiento sindical durante el siglo XX. Ganaron

\footnotetext{
${ }^{89}$ Idem.

90 «Colegio de Profesores: El turno de la Oposición», Análisis, n 124, año IX, 7 de enero de 1986, p. 11.

91 «Colegio de Profesores. Algo más que una elección», APSI, Santiago, nº 167, año 10, 2 de diciembre de 1985, p. 20.

${ }^{92}$ Entrevista a María Rozas, en Figueroa, op.cit., p. 43.
} 
las posiciones de "los partidos políticos que dirigían los inicios de la transición y eran los que pretendían conducir esta nueva etapa política del movimiento magisterial"93, excluyendo - como de todas maneras se haría a nivel de la alta política-, a los sectores de izquierda que no experimentaron una renovación hacia la derecha ${ }^{94}$. Por este motivo, desde 1986 hasta mediados de 1987 reaparece el fuerte debate en los docentes de izquierda respecto a cómo estructurar la unidad del magisterio ahora que ambas organizaciones son conducidas por la oposición.

\section{El rol de los profesores comunistas en la unidad del magisterio}

Desde la AGECH se realizaron numerosos esfuerzos por convocar a la unidad con los sectores que desde 1986 conducían el CdP. Durante ese año la AGECH envió 4 cartas privadas a la directiva del CdP para concretar la unidad mediante un Congreso donde las bases del profesorado discutieran los términos de ese proceso unitario, pero no recibieron respuestas, por lo que en noviembre de ese año hicieron pública una de esas cartas para dar cuenta de su vocación unitaria ${ }^{95}$.

Sin embargo, la exclusión del PC propiciada por el acuerdo de los sectores democratacristianos con el socialismo renovado, tensionaron la voluntad política unitaria de los profesores comunistas y de un sector del socialismo, puesto que la indiferencia hacia la AGECH obligó a aceptar jugar dentro del marco institucional del CdP, desechando el camino propio iniciado 6 años antes. Más que por el clamor de las bases, la autodisolución a regañadientes obedeció a una orden de partido, donde aceptaron participar en las siguientes elecciones del CdP de mediados de 1987; "como no hay voluntad política de apertura para recoger efectivamente todo lo que había sido la Agech, nosotros entramos a competir como izquierda dentro del Colegio"96.

De esta forma, rápidamente los profesores comunistas, socialistas de los sectores Almeyda e "Histórico", MAPU, MAPU-OC e Izquierda Cristiana, ya sea los que estaban en la AGECH como los que ya se encontraban en el CdP estructuraron una de las cuatro listas que participaron en esta nueva elección. Esto dio cuenta que primaba más la identificación partidaria que la cultura organizativa construida en la AGECH o en el CdP. De esta forma, la exclusión propiciada por la DC respecto en primer lugar a desarrollar un proceso unitario con la AGECH y, en segundo lugar, a propiciar una lista única de la oposición, provocó que los sectores comunistas que hasta ese momento habían desarrollado tácticas diversas en el

\footnotetext{
${ }^{93}$ Rodrigo Cornejo y Leonora Reyes, La cuestión docente: Chile, experiencias organizacionales y acción colectiva de profesores, Buenos Aires, Fundación Laboratorio de Políticas Públicas, 2008, p. 51.

${ }^{94}$ Rolando Álvarez ha insistido en que el proceso de renovación de las organizaciones de izquierda no fue unidireccional ni exclusivo de las corrientes socialistas, sino que también la radicalización del PC en los 80 representa un "proceso de renovación política e ideológica, distinto en contenidos y conclusiones al de sus aliados del Partido Socialista”, Arribas los pobres del mundo..., op.cit., p. 24.

95 “Jorge Pavez: Es urgente avanzar en la unidad”, Análisis, n 180, 22 de junio de 1987, p. 14.

${ }^{96}$ Entrevista a Jorge Pavez, en Cuevas, op.cit., pp. 90-91. Pavez fue ahora quien condujo en el magisterio comunista el proceso de autodisolución de la AGECH.
} 
magisterio, se concentraran en una sola lista, en una sola táctica, competir dentro del CdP como izquierda.

Los resultados de esta elección no fueron los que esperaban quienes habían participado en la AGECH: la lista sólo obtuvo 3 cargos nacionales — de un total de 15-, mientras la lista DC-PS "renovado" obtuvo 7 cargos y la lista oficialista 5.

Sin duda que el PC resultó ser el partido más fuerte en esta lista interna del CdP, al obtener 2 de estos 3 cargos, el de Jorge Pavez y el de Gorky Díaz ${ }^{97}$. En términos cuantitativos la votación de los candidatos comunistas ascendió de 3.720 en 1985 a 8.725 votos, representando el 13,7\% de la votación (muy superior al $8 \%$ de las elecciones del SUTE en 1972), siendo la tercera fuerza política tras la DC y la UNIGED (pro-régimen militar) ${ }^{98}$. Es decir, respecto a la elección anterior de fines de 1985 el PC había logrado sumar 5 mil votos, lo que refleja que gran parte del profesorado de la AGECH que ahora participó en la elección se inclinó por los candidatos comunistas ${ }^{99}$.

Todo esto se vivió mientras las tensiones del PC con los sectores socialistas en proceso de renovación hacia el centro se tradujeron virulentamente en el magisterio. Estos sectores comenzaron una inserción en la institucionalidad del régimen, mientras el PC era reacio a inscribirse en los registros electorales para participar en el plebiscito del año 1988, cuestión que incrementó las diferencias, al igual que el hecho de no abandonar las posiciones radicalizadas, ni rechazar explícitamente el uso de la violencia. Todas estas críticas del socialismo renovado se reflejaban en el magisterio a través de la revista "El Pizarrón" "100. En sus páginas se denostaba la falta de renovación, su proyecto radical y su adopción de "todas las formas de lucha", ante la cual se apelaba a que "las vanguardias que militan en la AGECH, en nuestra opinión, deberían hacerse una autocrítica respecto a su ideologismo y/o a su sectarismo" 101 .

Desde estos mismos sectores del socialismo renovado, en el contexto de las elecciones del CdP de junio de 1987, realizaron una severa crítica política a los profesores ligados a la estrategia del PC:

No apoyaremos la crítica fácil. No queremos dar paso al "maximalismo", a aquel que pide toda la democracia, que exige movilizaciones que nadie puede lograr, que quiere involucrar al Colegio en una posición de vanguardia que no haría sino aislarlo (...) [apoyaremos a quienes] apuntan

\footnotetext{
${ }^{97}$ Profesor oriundo de Concepción, representante de los sectores comunistas que siempre estuvieron en el CdP y no en la combativa AGECH de Concepción.

${ }^{98}$ Cox, op.cit., p. 25. La lista de izquierda en total obtuvo el $20,6 \%$ de los votos.

${ }^{99}$ Evitando ser mecanicista en la manera de entender el traspaso de votos de la AGECH al CdP, no deja de ser curioso que el PC fue el único partido de esta lista que incrementó su votación respecto a la elección pasada.

${ }^{100}$ Revista nacida en 1978 como "El Pizarrón de la Resistencia", siendo el órgano clandestino del MAPU Garretón en el profesorado. Luego ingresaron a participar en la revista militantes socialistas y del MAPU-OC. Todos sus miembros se harán parte de la renovación del socialismo, y la mayoría ingresará al Partido Por la Democracia (PPD).

${ }^{101}$ «La democratización del Colegio de Profesores», El Pizarrón, Santiago, n 37, marzo-abril de 1986, p. 11.
} 
a una alternativa educacional renovada, a quienes ya no defienden un añejo Estado Docente, como ideología del pasado hoy recurrente en muchos, sin que proyecten hacia el futuro una presencia estatal no burocrática ni centralizadora en la educación, combinada con formas participativas y comunitarias de propiedad y de administración de las unidades educativas y del sistema escolar ${ }^{102}$.

Esto reflejaba a nivel de la coyuntura política, que el PC a pesar de sus innumerables muestras de voluntad, fue radicalmente excluido en el año 1987 de la "transición a la democracia”, cuestión que también se experimentó al interior del magisterio.

Como si esto fuera poco, de manera paralela el PC se veía también tensionado internamente y por ambos flancos. Desde su flanco izquierdo, sufría una importante división de un sector mayoritario del FPMR que se alejó del partido; mientras que otro sector iniciaba un camino de acercamiento hacia la renovación socialista ${ }^{103}$. Fue en ese contexto, que en estas elecciones del CdP Pavez reconoce que independiente de los resultados "nos satisface porque hicimos una campaña sin ocultar nuestra condición de comunistas en un momento particularmente difícil" "104, cuestión que - contextualizada- hace nada despreciable los 8.700 votos obtenidos.

Estas diversas situaciones (fracaso del año decisivo, estructuración de una alianza de centro-izquierda que excluye al PC, triunfo de ésta alianza en el CdP, etc.) deja a la PRPM del PC en un muy mal pie a nivel político, por lo que las posiciones críticas al interior de este partido emergen y dejan de ser una minoría silenciosa, para tomar la iniciativa de una renovación acorde al resto de las organizaciones de izquierda ${ }^{105}$ que comienzan el abandono de las formas radicalizadas con posterioridad al año 1986.

\section{Consideraciones finales}

Las importantes tensiones generadas por la PRPM, se tradujeron en una carencia de táctica única de los profesores comunistas y en el desarrollo de una autonomía relativa a nivel del sindicalismo docente, donde fueron ganando desde fines de 1985 mayor apoyo partidario la idea de disolver la AGECH e insertarse en el CdP. Esto a pesar de que en ningún caso la AGECH había tocado su techo de crecimiento, sino que aún continuaba su extensión a pesar de que ya se cerraba el ciclo de las protestas contra la dictadura, pero que a contrapelo encontró al profesorado con masivas luchas contra la municipalización de 1986 y los miles de exonerados del año siguiente.

\footnotetext{
${ }^{102}$ El Pizarrón, Santiago, n 44, mayo-junio 1987, editorial, pp. 3-4.

103 Alfredo Riquelme, Rojo atardecer. El comunismo chileno entre dictadura y democracia, Santiago, DIBAM, 2009. Dentro del profesorado estas posiciones no aparecieron durante estos años, pero emergieron a inicios del siglo XXI para provocar una fuerte ruptura con la constitución de la Fuerza Social y Democrática. 104 "Elecciones: La prueba de los profes", Análisis, n 182, año X, 6 de julio de 1987, p. 21.

${ }^{105}$ Riquelme, op.cit.
} 
La exclusión propiciada por el eje DC-PS "renovado" hacia el profesorado comunista, no reforzó la tesis del paralelismo sindical, sino que por el contrario reforzó las críticas de los sectores comunistas que no habían optado por el camino propio. Desde estos sectores se evaluaba que la exclusión era propiciada por el hecho de haber levantado la AGECH, por lo que se debía sacrificar dicho proyecto.

De esta manera, los profesores comunistas cumplieron una vez más con un sello histórico de su militancia, su "mandato sacrificial" que refleja la obediencia partidaria a pesar de los discrepancias individuales a nivel de las bases. Con esta autoinmolación, con este sacrificio $^{106}$, los docentes comunistas postergan las ansias democratizadoras del magisterio, aquellas que les llevaron a la audacia de levantar una organización decididamente opositora a la dictadura, a pesar de las relegaciones, persecuciones y exoneraciones.

Esta situación significó rápidamente una desmovilización del profesorado, el cual para el año 1988 ya no se volvió a sumar a las protestas de la mano con los estudiantes secundarios, como lo había hecho en 1986. De manera similar, esto se tradujo en el continuo aumento que tendría la DC en las elecciones del CdP de 1989 y en el descenso del PC en 1.400 votos, representando la consolidación hegemónica de los sectores de centro en el sindicalismo docente chileno.

La AGECH se disuelve cuando el movimiento de profesores era masivo y seguía potente, por lo que podemos decir que sufrió una suerte de "frenazo" político partidario, el cual fue acatado por el profesorado, debido a la extrema persistencia de la vinculación partidaria en el sindicalismo docente chileno. En este sentido, es correcto el juicio de Cornejo y Reyes, al señalar que la AGECH "pese a la evidente presencia del Partido Comunista y del Partido Socialista-Almeyda (...) tuvo que terminar sometiéndose a la estructura del Colegio de Profesores en nombre de la unidad requerida por una transición democrática comandada por los cuadros dirigentes de los partidos políticos de la Coalición de Partidos por la Democracia"107, lo cual significó una derrota para las posiciones más rupturistas y audaces del profesorado. En esta misma línea, es que sostenemos que durante el periodo 1981-1987 los profesores comunistas gozaron de una mayor autonomía relativa para implementar la política del partido, autonomía que fue puesta en tensión en 1987 por la mayor importancia de las decisiones partidarias, cuestión que no se tradujo en disidencias ni resistencias a las decisiones partidarias, pero si en un fuerte debate interno.

Esta autodisolución a regañadientes es justificada partidariamente por el "mandato sacrificial", el cual se refleja en los testimonios que hablan de realismo o madurez política:

siempre tuvimos clara la tradición unitaria del movimiento obrero nacional. Justamente, esto fue lo que hicimos, porque en el minuto que

\footnotetext{
${ }^{106}$ Una perspectiva general del sacrificio del movimiento sindical chileno —en pos de la democratización de la sociedad chilena-, y la postergación sus aspiraciones inmediatas se encuentra en Francisco Zapata, "Transición democrática y sindicalismo en Chile", Foro Internacional, Vol. 32, n 5 (130), octubrediciembre, 1992, pp. 703-721.

${ }^{107}$ Cornejo y Reyes, op.cit., p. 49.
} 
hubo condiciones para eso, desembarcamos en el Colegio de Profesores. Hasta el día de hoy hay compañeros que nos miran feo porque disolvimos la AGECH, pues representó una fuerza material y subjetiva fundamental en tiempos de dictadura, pero era lo que había que hacer ${ }^{108}$.

En este sentido, la fuerte vinculación partidaria de las organizaciones sindicales se manifestó en todo su esplendor, ya que si bien las bases en su mayoría no compartían la autodisolución, no existieron casos de rebelión o desacato ante la medida sancionada en la VI Asamblea Nacional de la AGECH.

En dicha Asamblea se declaró al CdP, aunque fuese sólo como una resistencia discursiva: "como una entidad burocrática en su estructura y su accionar, que tiene afiliados pero no de base participativa, es amorfo, insensible frente a los problemas más sentidos, con carácter de Empresa en su estructura interna" ${ }^{\text {109 }}$. De esta forma, se puso fin a la carencia de táctica común organizativa de los docentes comunistas. Este hecho atípico en la historia de este centenario partido, se superó por la disciplina de sus militantes y sin casos de insubordinación, a pesar de las críticas internas. Esto da a entender que dentro de los profesores comunistas las diversas posiciones organizativas descritas, manifiestan que el partido no tuvo una táctica política definida hacia el profesorado, sino que más bien se permitió el debate y las formas creativas de implementación de su línea política.

En este sentido, la vinculación sindicatos-partidos que hemos destacado, no representa una subordinación de los primeros a los segundos, sino que precisamente consiste en una relación. La posición adoptada por los jóvenes docentes comunistas, de levantar una organización paralela al oficialista CdP no representa un grado de insubordinación, el cual habría sido inmediatamente sancionado, sino que fue una práctica organizativa de radicalización dentro de un proceso de diferenciación respecto al carácter organizativo institucional. Radicalización que fue fruto del giro del PC al llamar a la PRPM, la cual si bien es cierto tuvo serias dificultades para implementarse en el movimiento sindical y más aún en los docentes, difícilmente podía ser impulsada dentro de organizaciones completamente institucionalizadas como el CdP, por lo que los profesores comunistas que estaban dispuestos a realizar acciones más audaces o a apoyarlas dándole cobertura y masividad, no dudaron en levantar una organización paralela que se diferenciara de los límites impuestos por la dictadura.

Es por esto que planteamos que dentro de los docentes comunistas la posición que se impuso fue la del pragmatismo, motivada por la coyuntura más que por una cierta táctica política. Nos parece que los docentes comunistas durante este periodo experimentaron las mismas experiencias que el resto de la militancia comunista, es decir, vivieron un proceso de radicalización a inicios de los 80, de debate partidario interno, de exclusión por parte de los sectores DC tras 1986, para finalmente intentar insertarse a regañadientes en una

\footnotetext{
${ }^{108}$ Testimonio de Guillermo Scherping en Álvarez y Loyola (Editores), op.cit., p. 284.

109 Asociación Gremial de Educadores de Chile (AGECH), Situación actual de las organizaciones del Magisterio chileno. Vigencia de la AGECH. Informe de la 6ta. Asamblea Ordinaria, 23 de julio, Colegio de Profesores de Chile A.G., Santiago, 1987, pp.1-2.
} 
transición a la democracia que hasta el día de hoy no termina con los "amarres" de la dictadura.

\section{Referencias bibliográficas}

\section{Impresas}

Rolando Álvarez Vallejos, Desde las sombras. Una historia de la clandestinidad comunista (1973-1980), Santiago, Lom ediciones, 2003.

---------------, "La herencia de Recabarren en el Partido Comunista de Chile. Visiones comparadas de un heredero y un camarada del "Maestro". Los casos de Orlando Millas y Salvador Barra Woll", en Rolando Álvarez, Augusto Samaniego y Hernán Venegas (editores), Fragmentos de una historia. El Partido Comunista de Chile en el siglo XX. Democratización, clandestinidad y rebelión (1912-1994), Santiago, ICAL, 2008.

, Arriba los pobres del mundo. Cultura e identidad política del Partido Comunista de Chile entre democracia y dictadura. 1965-1990, Santiago, Lom ediciones, 2011.

--------------, "Las Juventudes Comunistas de Chile y el movimiento estudiantil secundario: un caso de radicalización política de masas (1983-1988)", en Rolando Álvarez y Manuel Loyola (editores), Un trébol de cuatro hojas. Las Juventudes Comunistas de Chile en el siglo XX, Santiago, Ariadna Ediciones, 2014, pp. 170-217.

Alan Angell, Partidos políticos y movimiento obrero en Chile, México, Ediciones ERA, 1974.

Asociación Gremial de Educadores de Chile, Documento base de discusión gremial. Cuarta Asamblea Nacional de AGECH, julio 1985.

Situación actual de las organizaciones del Magisterio chileno. Vigencia de la AGECH. Informe de la 6ta. Asamblea Ordinaria, 23 de julio, Colegio de Profesores de Chile A.G., Santiago, 1987.

Rodrigo Cornejo y Leonora Reyes, La cuestión docente: Chile, experiencias organizacionales y acción colectiva de profesores, Buenos Aires, Fundación Laboratorio de Políticas Públicas, 2008.

Cristián Cox y Cecilia Jara, Datos básicos para la discusión de políticas en educación. 1970-1988, Santiago, CIDE-FLACSO, 1989.

CPEIP, Censo Nacional de Docentes 1985, Santiago, 1986.

José Ángel Cuevas, Materiales para una memoria del profesorado, Santiago, Editorial Colegio de Profesores, 2002.

Andrés Figueroa Cornejo, La Asociación Gremial de Educadores de Chile, AGECH: Los profesores por la democracia y la dignificación de la profesión, Trabajo para optar al Título de Periodista, Santiago, Universidad de Santiago de Chile, 2002.

Julián Gindin, "Sindicalismo docente en América Latina: algunas consideraciones generales", en Julián Gindin (compilador), Sindicalismo docente en América Latina. 
Experiencias recientes en Bolivia, Perú, México, Chile y Argentina, Rosario, Ediciones AMSAFE Rosario, pp. 10-45.

Patrick Guillaudat y Pierre Mouterde, Los movimientos sociales en Chile: 1973-1993, Santiago, Lom ediciones, 1998.

V. I. Lenin, La enfermedad infantil del “izquierdismo” en el comunismo, Pekín, Ediciones en lenguas extranjeras, 1975.

Iván Ljubetic, Historia del magisterio chileno, Santiago, Ediciones Colegio de Profesores de Chile A.G., 2003.

Manuel Loyola, «El mandato sacrificial y la cultura política del comunismo chileno», Izquierdas, Año 1, Número 1, julio 2008.

--------------, "“Los destructores del Partido": notas sobre el reinosismo en el Partido Comunista de Chile", Izquierdas, Año 1, Número 2, diciembre 2008.

Christián Matamoros, "Represión e imposición organizativa. Los primeros años del Colegio de Profesores de Chile (1974-1981)", en Julián Gindin, Márcia Ondina Vieira Ferreira \& Sadi Dal Rosso (orgs), Anais do IV Seminário da Rede de Pesquisadores sobre Associativismo e Sindicalismo dos Trabalhadores em Educação, Niterói, Universidade Federal Fluminense, 18-20 de abril de 2013, Brasilia, Paralelo 15, 2013, pp. 105-120.

-----------, "Resistencias contrahegemónicas en el profesorado. Cultura política popular bajo la dictadura militar. 1976-1980", en David Aceituno y Baldomero Estrada (coords.), Miradas y reflexiones a nuestro pasado reciente. Actas de la I Jornada de Historia de Chile Contemporáneo, Edición Digital, Viña del Mar, Instituto de Historia PUCV, 2013, pp. 177-197.

Tomás Moulián e Isabel Torres, “¿Continuidad o cambio en la línea política del Partido Comunista de Chile?", en Augusto Varas (compilador), El Partido Comunista de Chile. Estudio Multidisciplinario, Santiago, CESOC-FLACSO, 1988, pp. 453-485.

Carlos Neely I., Crítica a la reforma educacional, Santiago, Pehuén Editores, 2001.

Iván Núñez, Gremios del magisterio. Setenta años de historia, 1900-1970, Santiago, PIIE, 1986.

Valentina Orellana Guarello, "Profesores rojos" y "amenaza soviética”. El alineamiento de la educación y la depuración de las escuelas durante la "guerra contra el comunismo" en Chile. 1947-1949. Tesis para optar al grado de Magíster en Historia, Santiago, Pontificia Universidad Católica de Chile, 2013.

Jorge Pavez Urrutia, Un hombre en la multitud. Recuerdos de un luchador social, Santiago, Das Kapital Ediciones, 2010.

Alfredo Riquelme, Rojo atardecer. El comunismo chileno entre dictadura y democracia, Santiago, DIBAM, 2009.

Jaqueline Roddick, The radical teachers. The ideology and political behavior of a salaried "middle class" sector in Chile, 1920-1935, Ph. D. Thesis, University of Sussex.

Jorge Rojas Flores, La Dictadura de Ibáñez y los Sindicatos (1927-1931), Santiago, DIBAM-Editorial Universitaria, 1993.

Luis Rojas, De la rebelión popular a la sublevación imagina. Antecedentes de la Historia Política y Militar del Partido Comunista de Chile y del FPMR 1973-1990, Santiago, Lom ediciones, 2011. 
Francisco Zapata, "Transición democrática y sindicalismo en Chile", Foro Internacional, Vol. 32, n 5 (130), octubre-diciembre, 1992, pp. 703-721.

---------------, Autonomía y subordinación en el sindicalismo latinoamericano, México, Fondo de Cultura Económica, 1993.

\section{Revistas y Periódicos.}

El Siglo, Santiago.

Solidaridad, Santiago.

Análisis, Santiago.

APSI, Santiago.

El Pizarrón, Santiago.

Las Últimas Noticias, Santiago.

\section{Entrevistas:}

Guillermo Scherping, 25 de enero de 2016.

Bernardo Medel, 15 de marzo de 2016.

Olimpia Riveros, 28 de julio de 2016.

Alejandro Sepúlveda, 28 de julio de 2016. 